\title{
Nurse teachers' perceived competencies in the context of students' first clinical placements: A qualitative study
}

\author{
Tatjana Zlatanovic ${ }^{* 1}$, Anton Havnes ${ }^{1}$, Sidsel Tveiten ${ }^{2}$ \\ ${ }^{1}$ Centre for the Study of Professions, Oslo and Akershus University College of Applied Sciences, Oslo, Norway \\ ${ }^{2}$ Department of Nursing and Health Promotion, Oslo and Akershus University College of Applied Sciences, Oslo, Norway
}

Received: June 8, 2016

DOI: $10.5430 /$ jnep.v7n1p32

\author{
Accepted: August 10, 2016 \\ Online Published: August 18, 2016 \\ URL: http://dx.doi.org/10.5430/jnep.v7n1p32
}

\begin{abstract}
This study seeks to illuminate the competencies of nurse teachers (NTs) and their operationalization in the context of clinical placement by exploring the challenges of being an NT, as experienced and articulated by diverse groups of interacting agents: NTs, mentors, and students. To gain insight into this area, we employed an interpretative qualitative approach, and applied data source and methodology triangulation: Focus group discussions with nurse mentors and students and e-mail interviews with NTs responsible for the placement learning were performed. Five main themes were revealed: NTs' personal and professional mastery, mastery of student support, mastery of mentor support, mastery of learning/teaching environment, and mastery of conditions while in the clinical placement. In addition, NTs emerged as coordinators, mediators, and moderators of a complex system. Within this system, the complex interplay of diverse components can have various facilitating or obstructing effects. Considering this complexity, we argue that part of those effects is directly connected to individual NTs' characteristics, combination of professional competencies, and application of these competencies in specific situations. We also propose that institutional and departmental contexts, as well as professional contexts of nursing practice and education, influence both teachers and students. Our research draws attention to the further development of organized and structured cooperation within and across institutions in establishing and maintaining links among different contexts of nursing education. With regard to placement learning, the complementary competencies of NTs and mentors, which mesh across fields and domains of expertise, appear to be a possible solution.
\end{abstract}

Key Words: Nurse teachers, Competencies, Professional development, Clinical placement, Focus group, E-mail interview

\section{INTRODUCTION}

Over the past few decades, higher educational contexts have experienced a growing call for competency-based education. Competencies have been seen as a combination of complex cognitive and higher-order skills, highly integrated knowledge structures, interpersonal and social skills, attitudes, and values, which, when acquired, enable professionals to apply them in a variety of situations and over an unlimited time span. ${ }^{[1,2]}$ The ongoing rapid development of the health-care delivery system, increasing complexity of patient situations, changes in treatment and work structures, increasing need for interdisciplinary collaboration, and complex problemsolving are some of the factors requiring practitioners to maintain and develop their professional competencies fur-

\footnotetext{
*Correspondence: Tatjana Zlatanovic; Email: tatjzl@ hioa.no; Address: Centre for the Study of Professions, Oslo and Akershus University College of Applied Sciences, Oslo, Norway.
} 
ther.

Abundant research exists on the competencies of nursing students and clinical specialists in specific nursing studies and literature, existing policies, and professional organization reports. However, the literature on the competencies of nurse teachers (NTs) (In this paper, the term nurse teacher is used for faculty-employed staff, whereas the term mentor refers to nurses employed by health institutions who are responsible for supervising students in clinical practice.) is relatively sparse. The most frequently used categorizations of NTs' competencies appear to include nursing competencies, pedagogical skills, evaluation skills, personality factors, and relationships with students. ${ }^{[3-5]}$ According to Tigelaar et al. ${ }^{[6]} \mathrm{NTs}$ ' competencies comprise of "an integrated set of personal characteristics, knowledge, skills, and attitudes that are needed for effective performance in various teaching contexts" (p. 255). Furthermore, the core components in facilitating effective clinical teaching are found in the relationships between the student, mentor, and NT. ${ }^{[7]}$ While literature emphasised that normative standards, as the National League for Nursing (NLN) Core Competencies for Nurse Educators (The NLN has systematized competencies as those facilitating learning, aiding learner development and socialization, employing assessment and evaluation strategies, participating in curriculum design and evaluation of program outcomes, functioning as a change agent and leader, pursuing continuous quality improvement in the nurse educator role, engaging in scholarship, and functioning within the educational environment. ${ }^{[9]}$ ), and the Australian NT professional practice standards (The ANTS ${ }^{[10]}$ outlined competency standards as teaching and learning, communication, professional practice, advanced nursing knowledge and expertise in the context of teaching, management and leadership skills in shaping and implementing change, and commitment to research and scholarship.), needs further investigation, ${ }^{[8,11]}$ this qualitative study is exploring the appreciation of perceived NT competencies for NTs, mentors and students. In fact, NTs' competencies are operationalized in compliance with the conditions and diverse institutional characteristics of teaching-learning environments. ${ }^{[12]}$ However, there is a lack of knowledge about how NTs' competencies are operationalized within the contemporary requirements and conditions in clinical placement and the characteristics of a teaching-learning environment. Given this background, this study seeks to illuminate NTs' competencies and their operationalization in the context of clinical placement-in particular by exploring the challenges of being an NT, as experienced and articulated by diverse groups of interacting agents. Explicitly, we ask the following research questions: 1) How do NTs, students, and nurses perceive NTs' competencies, and 2)

Published by Sciedu Press what competencies of NTs are appreciated in the context of their responsibility for students' clinical placement learning?

\section{Key perspectives}

The present study uses professionalization as its conceptual foundation and takes into consideration current research on professional education and the notion of progressive guided participation. Abbott ${ }^{[1]}$ defined professions as "exclusive occupational groups applying somewhat abstract knowledge to particular cases" (p. 18), adding that this type of knowledge is typically acquired in higher education. Professionalization is to some extent the process by which an occupation transforms itself into a profession. ${ }^{[1]}$ Standards for professional practice are clarified, group norms are established, and the professionals have some degree of influence on the certification of new generations of professionals. The professionalization of nursing is based on a liberal foundation and an extended trajectory of education. ${ }^{[13]}$ Professionalization also implies developing a theoretical body of knowledge so as to acquire defined skills, abilities, and norms; specific service provision; autonomy in decision-making and practice; and a code of ethics for practice. However, with nursing becoming a part of the higher educational system from the 1980s onward $^{[14]}$ nurse education have changed. Primarily, with the move to universities, nursing programs (once hospital based) are becoming integrated into higher education, which has led to increasing emphasis on academic knowledge. This transformation still stimulates several issues of debate. One such issue is that NTs are becoming more distant from clinical practice. Another issue is that as nurse education become a new professional sector, and a new specialization, it needs to be developed and specified. Furthermore, professional mobility, health sector reforms, and public concern with the quality of health-care services are leading to considerable interest in international standards for nurses. Governments are also focusing on implementing inclusive movements for educational harmonization. ${ }^{[15,16]}$ Simultaneously, research on teaching in higher education is steadily increasing, and attention is being progressively given to enhancing the quality of teaching ${ }^{[17]}$ and bridging the gap between students' education and experience in professional education. ${ }^{[18-21]}$

As Colby et al. ${ }^{[22]}$ argued professional education must provide both, the experiences and the reflection on experienced in professional education, to ensure that students are able to make the best possible decisions in distinct times, places, and circumstances, based on solid theoretical understanding, knowledge about recent developments in research, and critical reflective awareness of practical situations. Educating nurses implies including neophyte students-who enter the nursing program with vague, incomplete, and to some 
extent inappropriate perceptions about their future profession-and guiding them through a challenging process of development. Whereas the nursing program sets the standards, a key role of NTs is to guide students from such a stage of incomplete insights to a level of professional competence that allows them to enter the nursing profession. In the context of their education, students are guided through a process of increasing levels of participation, from peripheral to full participation. ${ }^{[23]}$ A basic understanding of Vygotsky's ${ }^{[24]}$ notion of the "zone of proximal development" offers a possible approach by which to frame this gradually progressive guided participation. According to Vygotsky, this implies setting expectations that establish a "distance between the actual developmental level as determined by independent problem solving and the level of potential development as determined through problem solving under adult guidance, or in collaboration with more capable peers" (p. 86). As students reach a new, more advanced level of independent problem-solving, new expectations or achievement goals are set. Nurse education can be seen as such a process of guided participation with increasing levels of expectations, monitored and regulated by NTs - and in collaboration with placement mentors in placement learning. This article aims to explore NTs' competencies from the perspective of the NTs' roles of teacher, mediator, and moderator in placement learning.

\section{Methodology}

\subsection{Design}

The design of this study was explorative and descriptive. To answer the research questions, we employed an interpretative qualitative approach underpinned by a philosophical perspec- tive derived from Gadamer's ${ }^{[25]}$ hermeneutics. Triangulation of data sources and methods were applied.

\subsection{Setting and sample}

This study was conducted on three nursing education campuses in Norway and at four different sites in municipal health institutions involved in the realization of the first clinical placement period. Differences in curricula existed, with Campus I and Campus II applying the same program and Campus III following another curriculum.

The study involved focus group discussions (12) with nurse mentors (10) and students (46), as well as e-mail interviews with NTs (5) responsible for this placement learning. The total number of participants in the focus groups and e-mail interviews was 61. Data were gathered from January through March 2015. Based on indications from recent research regarding the differences in levels of involvement, accountability, and commitment between permanent and seasonal staff within academia ${ }^{[26]}$ we had NTs' permanent employment status as the only criterion for selection of NT participants. The heads of studies selected the NTs using a snowball-sampling technique. The placement coordinators within the nursing education institution selected the students and health institutions, and the placement coordinators within the health institutions selected the nurse mentors. Participation in the study was voluntary. The researchers had no influence on these selections.

\subsection{Data collection}

The distribution of sites and participants in the data-gathering process is presented in Table 1.

Table 1. Distribution of sites and participants in the data-gathering process

\begin{tabular}{lll}
\hline Campus I & Campus II & Campus III \\
$\mathbf{1}$ nursing home, $\mathbf{3}$ departments & $\mathbf{1}$ nursing home, $\mathbf{4}$ departments & $\mathbf{2}$ nursing homes, $\mathbf{6}$ departments \\
\hline 2 focus groups with students & 2 focus groups with students & 4 focus groups with students \\
1 focus group with mentors & 1 focus group with mentors & 2 focus groups with mentors \\
2 e-mail interviews with NTs & 1 e-mail interview with NT & 2 e-mail interviews with NTs \\
\hline
\end{tabular}

As we understood that the diversity of participants within the same focus group might affect the data (e.g., nursing students might be inhibited by the presence of a nurse mentor), focus groups involved students or nurse mentors only. Furthermore, the groups were "naturally" formed from preexisting groups of students fulfilling their placement requirements within the same department and from the involved nurse mentors. Thus, the composition of each of the performed focus groups reflected everyday interactions; the groups were familiar and stable. The main goal was to facilitate interaction and an open conversation about various aspects of the study. The conversations following from each initiated topic (see Table 2 ) proceeded in various directions in the discussions. The approach in the focus groups was consistent. I.J., MSc, was a facilitator of the performed focus groups; he is not an author, as he did not contribute to the paper. The first author was a moderator of the discussions. Member-checking was used in form of respondent validation: the summaries of the discussions presented at the end of each of the performed focus groups provided the participants with opportunities to 
comment on their responses.

E-mail interviews were conducted with NTs who worked with students and mentors in clinical placement and were familiar with the students' knowledge, skill, and attitude development, as well as evaluation of the students' performance in clinical placement. E-mail interviews were carried out as a way for NTs to elaborate on and discuss certain issues surrounding the supervision of students in placement learning that they may not feel comfortable addressing in a group discussion setting. The e-mail correspondences were more structured than the focus groups, although with the same themes. Open questions provided the participants with opportunities to describe issues freely. The e-mail interviews also allowed the participants to review and revise their responses. The focus group discussions were audiotaped and transcribed verbatim; the participants and the institutions were anonymized in the transcription process. The e-mail interview data were included verbatim.

Table 2. Focus group discussion theme guide with mentors - an example

Entry question
1. About motivations, responsibilities, and expectations
Why have you chosen to be a nurse mentor, and what does it take to succeed as a nurse mentor?
Focus group discussion
2. About the nursing profession
Can you discuss what a good nurse is
What does it mean to be a professional nurse?
3. About knowledge and learning
Can you discuss your experience with integration of theory and practice
How relevant is that learned at school in the practical field? Example?
What does it take to succeed as a nursing student?
4. About evaluation, learning outcomes, and development
Can you discuss your experience with evaluation
How to best obtain knowledge about student learning/development?
Are learning outcomes important for learning and student development through the study program?
5. About NTs
Can you discuss your experience with NTs
What is a good NT? What does it mean to be a professional in an NT role?
What does it take to succeed as an NT?

\subsection{Ethical considerations}

Approval for this study was granted by the Norwegian Social Science Data Services (NSD), project number: 39757. The NSD's regulations for data handling and ethical guidelines were strictly followed, with ethical issues receiving close attention throughout the study. ${ }^{[27-30]}$ The nursing educational institution gave permission for NTs and students to participate in this study. The head of the Department of Nursing in the relevant municipal health institutions gave permission for nurses from these institutions to participate in this study.

\subsection{Analysis}

An inductive approach was applied to the data material. The analysis was oriented to reach an understanding through a systematic dialogue with the participants' text and was conducted in three interrelated processes - thematic analysis, analysis of exemplars, and a search for patterns. MAXQDA11 software ${ }^{[31]}$ was used to organize the data.

(1) We began the analysis with familiarization with the data body and identifying themes emerging from the raw data. The goal was to create descriptive categories, from which a framework for analysis could be formed. We imported transcriptions of discussions conducted with the students and mentors, as well as e-mail interviews, into the software. ${ }^{[31]}$ We grouped words, phrases, and events that appeared to be similar into the same category, which became partly modified during further analysis.

(2) Each coding profile, including a description of the code and its function, applications, and examples, was discussed within the research team. Coding consistency was checked by the three researchers and then applied to the whole body of data. When codes were defined, we extracted the code systems for each set of data, as well as a quote matrix for each of the identified themes. The intended outcome of this process was to create summary categories, which captured the key aspects of the themes in the data material and which we found to be the most important themes given the 
research questions. When the raw data were broken down into meaningful categories, we identified them according to the context. Each identified theme was then related to the meaning of the whole text. ${ }^{[25]}$

(3) We reexamined the identified categories to determine how they were connected. After rereading the quote matrixes, we made a summary of the identified quotes for each identified theme of the conducted discussions and the e-mail correspondence. This allowed for horizontal (across the themes) and vertical (across the participants' groups and campuses) analyses: we first analysed each individual data set before looking for interrelations, co-occurrences, and contrasts between participants' groups and between campuses. Significant patterns emerged from their similarities or deep contrasts, as a source of the final main themes. The emergent subcategories were, in this process, reduced to 12 through merging of some of the smaller subcategories. In this stage of the analysis, we also explored similarities and differences across subgroups (e.g., specificity of local practice versus NTs' accessibility). Finally, we abstracted those 12 categories into five main themes.

\section{RESULTS}

The analysis revealed five main themes: NTs' personal and professional mastery, mastery of student support, mastery of mentor support, mastery of learning/teaching environment, and mastery of conditions in clinical placement. These themes are presented in Table 3 .

Table 3. Results: main themes, subcategories, and their descriptors

\begin{tabular}{|c|c|c|}
\hline The & Subc & Descriptor \\
\hline $\begin{array}{l}\text { NTs' } \\
\text { professional } \\
\text { and personal } \\
\text { mastery }\end{array}$ & $\begin{array}{l}\text { - NTs in clinical } \\
\text { placement } \\
\text { - } \quad \text { Commitment }\end{array}$ & $\begin{array}{l}\text { - Nursing and pedagogical competencies; value of PhD measured by teacher's } \\
\text { - } \quad \text { The key link; nursing expertise, pedagogical competencies; management } \\
\text { and cooperation; communication: involvement in decision-making; } \\
\text { collegial culture } \\
\text { - Motivation, interest, engagement, availability, openness, and invitation to } \\
\text { dialog; role model }\end{array}$ \\
\hline $\begin{array}{l}\text { Mastery of } \\
\text { student support }\end{array}$ & 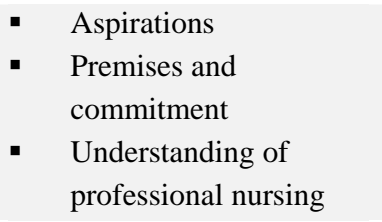 & 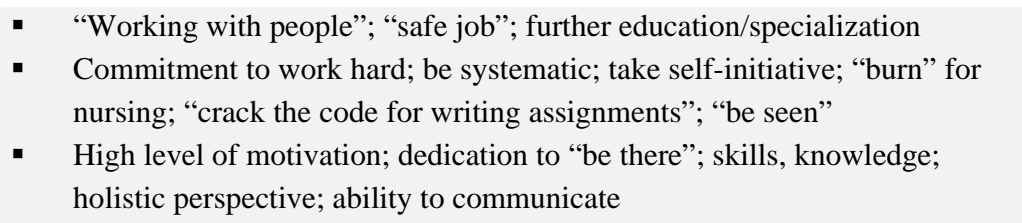 \\
\hline $\begin{array}{l}\text { Mastery of } \\
\text { mentor support }\end{array}$ & $\begin{array}{l}\text { - } \quad \text { Preparation for students } \\
\text { - } \quad \text { Commitment and } \\
\text { qualifications }\end{array}$ & $\begin{array}{l}\text { - Familiarity with the plan for clinical placement and defined learning } \\
\text { outcomes } \\
\text { - Courses in supervision and an evidence-based practice; motivation; role } \\
\text { models; demonstration of good nursing practices; application of knowledge } \\
\text { in clinical situations; demonstration of positive attitudes; positive influence } \\
\text { on students' learning and their own practice }\end{array}$ \\
\hline $\begin{array}{l}\text { Mastery of } \\
\text { learning/ } \\
\text { teaching } \\
\text { environment }\end{array}$ & $\begin{array}{ll}\text { - } & \text { Learning } \\
\text { - } & \text { Study program }\end{array}$ & $\begin{array}{l}\text { - Group work, seminar days, and colloquium work; lecturing; relevance for } \\
\text { practice; realization of learning goals and workload; evaluation } \\
\text { - Program designed to be interesting and demanding and highly motivating; to } \\
\text { work hard and be systematic; curricula and integration }\end{array}$ \\
\hline $\begin{array}{l}\text { Mastery of } \\
\text { conditions } \\
\text { while in clinical } \\
\text { placement }\end{array}$ & $\begin{array}{l}\text { - Theory/research/ } \\
\text { practice integration }\end{array}$ & $\begin{array}{l}\text { - Nursing homes: shortages in nursing staff; high levels of responsibility for } \\
\text { nurses; lack of possibilities to influence the cotemporary situation; nursing } \\
\text { home image in society; leadership, existing culture } \\
\text { - Situation in departments influenced by level of education, attitudes, and } \\
\text { demographical differences among staff; theory/research/ practice } \\
\text { integration }\end{array}$ \\
\hline
\end{tabular}

Table 3 indicates diversity of commitments, sets of priorities and diversity of competencies, implying NT as coordinator and mediator of diverse agents' engagements and interactions. In the following sections, we describe how these main themes were addressed. The themes contain views of NTs, mentors, and students, with a main intention to explore challenges that NTs need to address. These are illustrated, drawing on statements from some of the participants (The 
quotations are identifiable, for example, FG1 is for focus group number 1, S1 is for student number 1, T1 is for NT number 1, and M1 is for mentor number 1.).

\subsection{NTs' professional and personal mastery}

This theme, central to NTs' self-monitoring and selfregulation, emerged from the subcategories of NTs' competencies, NTs in clinical placement, and commitment. The NTs' ability to illustrate theory with examples from recent nursing practice was highly rated by all groups of participants. Subsequently, all respondents appreciated NTs who were highly competent nurses, as well as the NTs' ability to interact effectively with health-care professionals in the clinical placement. Multiple components of pedagogical competencies were emphasized, for instance, in modifying expectations and approaches to students' levels of learning, lecturing and organizing training post hours, and giving feedback, while NTs' interest, engagement, availability, openness, and invitation to dialog emerged as crucial for effective learning. NTs' academic competencies were met with ambivalence. Some of the students and mentors connected academic competencies to $\mathrm{PhD}$ research, which they found to be less relevant for practice than nursing competencies. Based on the students and mentors' perceptions, the relevance of PhD-level of NTs to teaching depends on the NTs' research focus.

Reflecting on her own style, one NT commented that she needed to "be a role model in the nursing profession with my way, style, manner of interacting with students" (T3). Several students (e.g., FG8S3, FG9S2) referred to the "good NT", whom they described as an NT who is familiar with local practices, appreciated by staff, knowledgeable about students' individual needs, position, and capacity, has a "burning" for the profession, and is open, patient, and available to students. The accessibility of NTs during clinical study appeared to be crucial for students (e.g., FG6S5, FG10S6). The students and NTs also emphasized the importance of NTs' involving and valuing students' contributions (e.g., in the evaluation of students' experiences in clinical placement).

The NTs' description of their own motivation for teaching varied from undefined to the possibility of performing research, to an interest in specific nursing disciplines, to a strong commitment to the teaching of nursing:

I am deeply committed to this genius profession. I see how vital nursing practice and a holistic view of humankind are. As a teacher, I can share knowledge and motivate others. (T3)

All respondents emphasized engagement, openness, provision of constructive feedback, proper preparation, and evidence-based pedagogical practice as key dimensions of
NTs' competencies. Furthermore, it was important to "request evaluation and be receptive to feedback from both students and colleagues" (T3). Within a wider context, other crucial aspects of success in the NT role emerged in collegial culture, including mutual support, and shared knowledge and understanding, as well as the opportunity to engage in discussions on subject materials. One NT noted, "We need professional nursing and pedagogical supervision where we can highlight challenging situations ... and learn from each other" (T1).

\subsection{Mastery of student support}

This theme emerged from the subcategories aspiration, premises and commitment, and understanding of professional nursing, and draws the attention to student characteristics that NTs need to address. NTs' mastery of student support involved monitoring and regulating students' learning, engaging with students' aspirations, developing students' commitment to the nursing profession by emphasizing the value of a strong work ethic and a dedicated demeanor, selfassessments, and promoting collegial involvement among peer-students.

The students' engagement with learning was associated with their aspirations for becoming a nurse. Insights into students' motivating factors, who they are, and what drives them to become a nurse, can be seen as essential for NTs in their monitoring and support of students' learning. Most students reported that they were attracted by the nature of nursing (hereunder "working with people"), close involvement in patient situations, and a wish to make a difference in the lives of people in vulnerable situations. Some of these students were "inspired by" their own or family members' health problems, as well as by family members who were/are in the nursing profession. Others had previously worked as assistants at health institutions and wished to pursue professional development in the same field.

Likewise, knowing the diversity of students' expectations about their future career emerged central to successful student support. For instance, many students underlined the possibility of further development as crucial. They mentioned the possibility of specialization and the necessity of learning throughout the rest of their working lives as attractive elements of nursing. Some students were motivated by the possibilities of studying and working abroad. Some of the students chose to study nursing "because it provides a safe job" (e.g., FG9S1, FG9S6), adding that this could not be the only motivation. The topic of students' diversity in terms of student profile and weak prior knowledge arose spontaneously. One mentor lamented, "Suddenly, it becomes very easy to get into! It was not before!" (FG2M4). Another 
mentor echoed this sentiment, stating, "I'm just thinking how sad it is that anyone can get into nursing college" (FG1M2). However, teachers, mentors and students shared the view that to succeed, students need to work hard, be systematic, take self-initiative, and "burn" for nursing. One student laminated:

... it's academically solid study, something is happening all the time, you must keep up to date on the relevant procedures and the know-how, research is going on all the time. Therefore, I think, I like nursing so well. (FG7S4)

The majority of the students expressed that a feeling of mastery of theory and practice is important and that different teaching methods linking theory and practice are available. Support from other students was also highlighted. Like the students, the NTs emphasized that students need to be familiar with each other and that confidence "is key for daring to be themselves and to learn" (T3). Furthermore, receiving individual feedback was regarded by the students as central for success in the student role. One NT commented that to succeed, students must "crack the code for writing assignments" (T1). Another NT stated, "To succeed as a nursing student, the student needs to be seen, taken seriously, and meet by teachers" (T3).

Across the groups of informants, the final aim of nurse education-educating young people with limited prior experience and knowledge to become a professional nurse who is highly motivated to work with people in vulnerable situations and has the capability to "be there" (i.e., to be emotionally available) for their patients-was emphasised. A professional nurse was described as a person who has up-to-date knowledge and skills and an attitude based on a holistic perspective. In addition, participants connected professionalism in the nursing role to conveying a neutral appearance, to maintaining a professional distance, and to communicating and "relating to others so that others feel taken seriously and understood" (T4). The need for ongoing support from NTs in developing and maintaining such a high level of commitment was illuminated.

\subsection{Mastery of mentor support}

The discussions indicated how important it was for NTs to know the students' mentor, and share with them the responsibility of supporting students' placement learning. NTs' mastery of mentor support emerged from aspects of preparing mentors for students, and mentors' commitment, and qualifications. The level of preparation of mentors and clinical placement for students varied between campuses and health institutions. All participants indicated an appreciation of preparation for students, which included a certain predictability and flow of information about students and learning outcomes. One mentor commented, "We got information about what students have learned [prior to their placement], what kind of procedures [they have learned], and how far they are in their program. It was very nice". (FG2M1) The discussions also revealed some problem areas associated with the preparation for placement learning. For example, the mentors from the Campuses I and II indicated that meeting before the clinical placement is for leaders, not directly involved with the students during their placement learning, highlighting importance of involving actual actors in preparation processes.

Furthermore, the discussions showed that mentors, who had completed courses in supervision and an evidence-based practice, were familiar with the plan for placement learning and defined learning outcomes, advancing both, students' learning and their own practice. However, one issue was that the mentoring was often provided by assisting personnel or by professionals with a background other than nursing, while the nurses followed students more externally, through random meetings. Those situations were challenging. Furthermore, there was a common understanding among all participants' groups that "good mentors" (e.g., FG8S3, FG9S2) in practice were good role models, demonstrated good nursing practices, applied knowledge in clinical situations, demonstrated positive attitudes, and had a clear purpose when working with students. One student described her mentor's approach as follows:

She is academically strong, and she comes with many tips... explained, yet she did not give me answers, but she asked why I had done things... she demanded of me. (FG12S3)

NTs' perceptiveness to mentors' aspirations and qualifications appeared as basis for cooperation and a precondition for enhancing students' learning.

\subsection{Mastery of learning/teaching environment}

This theme emerged from the subcategories of learning (including realization of learning goals and workload, evaluation in practice) and study program.

All the students commented that learning was best achieved through group work, seminar days, and colloquium work, implying need for change from traditional pedagogy to the student active learning methods. Furthermore, the students within Campus III found lecturing to be an integral component of their learning, goal oriented and examination directed, providing a better orientation toward what and how to approach the learning process. The students from the other two campuses described lecture-based learning as a waste of time if the NT was not engaged in and knowledgeable about the 
topic, suggesting appreciation of NT who maintain clinical understanding.

At two of the campuses, the realization of learning goals in clinical placement was described as impossible to achieve owing to students' heavy workload. The NTs shared the view that giving students many predefined assignments and tasks did not necessarily support their learning. One NT made the following acknowledgment: We have not taken into account that it takes time to be in practice, it takes time to read, and it takes time to write assignments. When it is too much to do, it at once becomes very superficial. (T1)

Furthermore, the students from these two campuses and one of their NTs commented that an eight-week clinical placement focusing only on self-care activities was too long. The participants from Campus III did not consider the length of the practical period to be an issue. The focus of their placement learning and achievement expectations differed from those of the other two campuses owing to variations in the curricula. For instance, they viewed clinical placement requirements as steppingstones to achieving learning outcomes - they appeared to be essential tools for operationalizing the students' activities and a basis for evaluation.

The discussions showed that the evaluation of placement learning also varied. In two departments within one institution, evaluation was organized in groups, based on the assumption that it would be more effective, whereas in all other places, it was individualized. In the different campuses, the mentors' presence and role in the evaluations varied. The focus of the evaluation appeared to be on either the evaluation scheme itself or the student (e.g., FG4S1). One student noted, "It was really focused on the form, very little on what I really learned" (FG5S3). In Campus III, the evaluation was described as a situation in which totality was estimated, giving the students a clear understanding of certain issues and what they should focus on further in the practical period. At the same time, evaluation of placement learning required a high level of responsibility from the NTs. One NT described the situation as follows:

A teacher must be aware of [one's] own responsibility to stop students who are not suited or do not have enough knowledge to continue to the next stage of education. It is a big responsibility and a demanding part of work as an NT. (T2)

The nature of the study program required the integration of a wide variety of separate elements into practical situations. The discussions showed that the study program was quite interesting and extremely demanding, requiring hard and systematic work. Students' success depended largely on their level of effort. However, NTs were expected to inspire

Published by Sciedu Press students to become highly motivated, engaged, inspired, and interested. From the first day of the program, students had to be guided to take responsibility for their own learning. Overall, the NTs were in agreement regarding students and mentors' discussions:

It is a hard study [program]. I think it always has been. One must be able to acquire a critical sense and ability to think logically. There is another advantage to be practically oriented and able to express oneself well in writing also. (T1)

The NTs also emphasized the need for proper operationalization of curricula. In doing so, one NT stated, "lessons are complemented, and we can build upon each other" (T4). Another NT observed, "For education to be good, teachers must make each other good" (T3). NTs' acknowledgment of the need for team approach, as well as recognition of the demands set out in the curricula emerged as a precondition for setting the stage for advancing students' critical thinking, situational action, reflexivity and clinical reasoning in placement learning.

\subsection{Mastery of the conditions in the practical placement site}

The description of the conditions in the practical placement sites included the clinical placement and level of theory/practice/research integration. Described variation across nursing homes and situations in departments within nursing homes required NTs to deal with constraints and create affordances, thus emerging as a starting point in operationalizing NTs' competencies.

The students and mentors discussed the differences among nursing homes, based on their introduction to placement learning or previous work experiences. However, shortages in nursing staff, high levels of responsibility for nurses, and lack of possibilities to influence the cotemporary situation appeared to be common. Furthermore, nursing homes as a workplace emerged still somewhat stigmatized in that it was associated with a low level of education among non-nursing staff. Furthermore, the increased complexity of patient care situations added to the already high level of responsibility expected of the nurses. The described differences between nursing homes and their departments were mostly experienced in relation to the leadership, existing culture, and the level of competencies among staff. The experiences were similarly described within the same campus. For example, a student from Campus III emphasized the importance of earning practical experience, stating, "I think that it is very good practice, with a lot of challenges, a lot to learn, and it is good to be with all those who work here, not just mentors" (FG11S1). 
Theory/research/practice integration helped to engage students. All participants described the relevance of theory to practice as a key to becoming a good nurse. One student remarked that it was necessary "to know theory before we go into practice" and that "when I am out in practice, I can use it [theory] and I understand the totality of it" (FG8S1). However, the discussions indicated differences in the levels of knowledge and interest in the profession. One student noted, "Some are more likely fixed at what they learned 30 years ago, but some are very innovative, very curious, think that it is very exciting to follow up, to attend courses" (FG11S4). Another student observed, "There is a difference in the level of knowledge.... The new nurses are much better at performing what they have learned" (FG5S1). Hence, the level of education, attitudes, and demographic characteristics among staff may be of central importance for NTs in the overseeing clinical placements.

\section{Discussion}

This study investigated the challenges of being an NT, as experienced and articulated by diverse groups of interacting agents. Building and maintaining relationships between the individual students, mentors, and NTs, as well as NTs' relationships to the relationships of others (students and mentors), emerged as critical to the participants' perceptions of NTs and NTs' commitment to the commitments of others. The operationalization of NTs' competencies appeared to involve the following: 1) NTs' personal and professional mastery, and the building and maintaining of relationships approved on premises set by the nurse education program;2) mastery of student support while valuing their premises and commitment, as well as dealing with students' incomplete knowledge and lack of skills at that stage in their learning; and 3) mastery of mentor support while appreciating their qualifications and the practical (situated) skills. Beyond relationships, context factors such as the conditions of the clinical placement site and the characteristics of the learning/teaching environment, each with specific opportunities and constraints, emerged as essential. Figure 1 provides an illustrative model of this complex interrelationship - illustrates the components of active building and maintenance of the learning environment, with the NT occupying the primary position of responsibility.

NTs emerged as coordinators of a complex system. Their responsibilities involve identifying the components of the system and the system as a configuration of these components, as well as monitoring and enacting upon the system, including its diverse components. We found these components (the main themes) to be highly integrated. Issues arising from the complexity of this integration are addressed later in section

\section{4.}

In this section, we discuss the findings in relation to the key perspectives and the existing research. First, we link the NTs' competencies to the mastery of the learning/teaching environment. Second, we discuss maintaining and expanding students' aspirations and commitment, relating the NTs and mentors to shared agenda and commitment to students' learning. Third, we highlight how to deal with contextual opportunities and constraints. Finally, we attempt to widen the perspective on NTs and examine some methodological considerations.

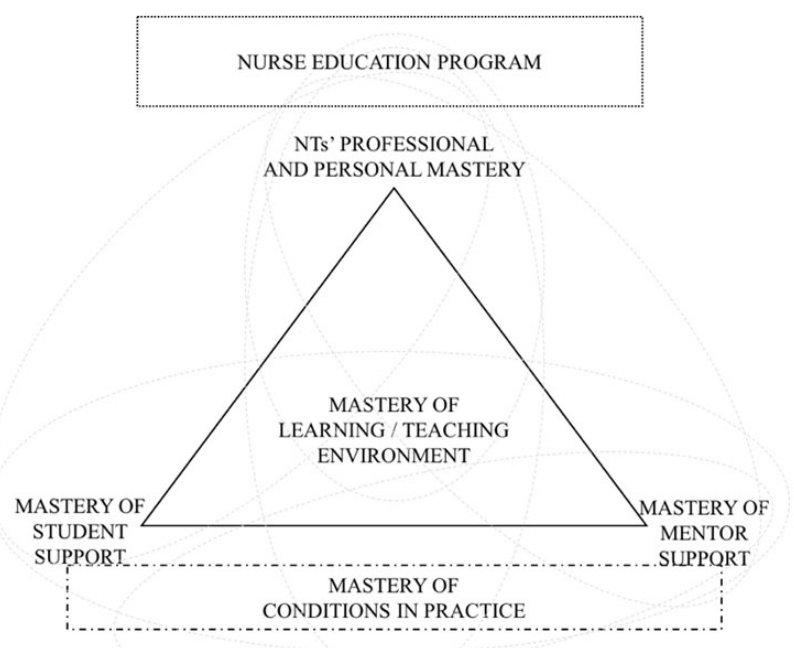

Figure 1. Representation of themes related to students', mentors', and NTs' perceptions of NTs' competencies, as well as NTs' competencies and their operationalization during students' first clinical placement

\subsection{NTs' competencies and mastery of learning/teaching environment}

The NTs' approach to their own competencies was found to be central to their self-monitoring and self-regulation, namely, in relation to their motivation and commitment for teaching nursing, their perceptions on how to succeed not only as an NT but also as a student, and their influence on decision-making in the program. These themes appear to be unexplored in recent studies concerning NTs' competencies. It is, however, well documented that job satisfaction, a sense of control within the work environment, innovative behavior, and an ability to initiate change are associated with dimensions of empowerment. ${ }^{[32-34]}$ Simultaneously, NTs' sense of psychological empowerment influences the use of empowering teaching techniques. ${ }^{[35]}$ Nonetheless, the empowering of others appears to be essential for driving students' learning and critical for preparing graduates to meet the constantly changing demands of health care responsively 
and accountably. Furthermore, a sense of autonomy and authority develops from a professional attitude and way of working, ${ }^{[36]}$ as well as from an orientation toward the active shaping of the profession. ${ }^{[1,13]}$

We found that NTs' competencies in placement learning were connected to nursing competencies, pedagogical skills, management, and cooperation. In relation to first-year nursing students, NTs' attitudes and accessibility were seen as crucial. These findings partly correlate with previous studies in the field. ${ }^{[3-6,11]}$ The NTs' approaches to teaching and ability to operationalize and support students' learning and development in given situations are seen as deeply related to the students' educational experiences ${ }^{[19]}$ and pedagogical aspects of NTs' competencies.

Generally, those instances where NTs' contribution to students' learning and development was experienced as empowering coincided with the display of NTs' personal characteristics, professional attitudes, and updated, integrated practical and theoretical nursing and pedagogical competencies, as well as high levels of cooperation and management abilities. The NTs were viewed as mediators in the complex interplay between the clinical and university settings, with flexibility of professional performance in specific situations being considered a precondition. Interestingly, academic competencies (as the development of research-based knowledge to inform practice) were not a precondition for being a good NT, as seen by the students and mentors. However, the NTs expressed the necessity of working from an evidence base. This finding may be explained by the fact that academic requirements for NTs are relatively new. Another explanation is that outside "the academic world," it is still not broadly known what academic competencies include and their relevance to professional practice for both teaching in nursing and nursing as a profession. A key challenge for NTs is bridging the gap between academia and the world of practitioners while ensuring the quality of the teaching team. The existing literature views research involvement as an integral part of the role of teachers ${ }^{[37,38]}$ and academic nursing ${ }^{[39,40]}$ as a necessity. Nonetheless, to succeed in the dual role of academic, who is engaged in academic activity, and nurse, who contributes to the discipline and profession of nursing, one's performance has to be recognized as legitimate to others who inhabit the domains of both academia and nursing. ${ }^{[41]}$

\subsection{Maintaining and expanding students' aspirations and commitment}

The responses emphasized that NTs' personal mastery and professional mastery were highly related to students' learning/teaching experience. The development from student

Published by Sciedu Press to professional nurse was also highly related to students' premises and commitment, as well as to the nature of the nursing study program. Education then represents an encounter between students' preexisting perceptions and expectations of what it means to be a nurse and the ways in which this is manifested by NTs and mentors, as previously indicated by Terum and Heggen. ${ }^{[21]}$ NTs' mastery of students was essential in securing individual support in students' engagement in nursing knowledge and practice, thereby providing understanding for the challenges of learning and development involved in becoming a nurse. However, the responses pointed to the relevance of the heterogeneous level of academic preparation and aspirations for success in the nursing students' role. Nonetheless, a high level of heterogeneity among students implies adjusting teaching approaches to meet individual students' needs, while the intense massification of nursing education may have a negative impact on the quality of professional nursing.

In the description of the professional nurse, a shared understanding emerged in all participants' groups, regardless of the setting (practical sites or campuses). However, the description of the professional nurse within nursing homes appeared complex, particularly regarding current nursing functions. A highly independent mastery of concrete patient situations, different levels of interdisciplinary collaboration in health provision, and management of human and material resources was also expected, as stated in the literature. ${ }^{[13,42,43]}$ In cases where the clinical placement length was an issue, the focus on requirements in placement learning was not found to be compatible with these nursing functions, nor with recommended approaches to gradually progressive guided participation and framing of new expectations or achievement goals. ${ }^{[24]}$ NTs' capability to maintain and expand students' motivation and commitment appeared linked to the students' success in their study program. During clinical placement, NTs share this responsibility with mentors. Recent studies have emphasized the crucial role of mentors and NTs in quality of placement learning. ${ }^{[4,45]}$ Our findings partly correlate with recent research. ${ }^{[7]}$ In addition, our results indicate specifically that a supervision course for mentors and updated evidence-based practice are necessary for the successful mentoring of nursing students in clinical placement. The students and NTs participating in this study highly appreciated the mentors' qualifications and practical (situated) skills. Furthermore, the NTs' familiarity with the mentors appeared to facilitate the sharing of responsibility for students and enhance commitment to students' learning. This, in combination with the diverse attributes required from today's NTs, underlines the importance of cooperative and collective actions and a supportive working environment. 


\subsection{Dealing with contextual opportunities and con- straints}

The availability of mentors, effective clinical placement organization, and operationalization of activities were necessary preconditions for "good" placement learning for nursing students. Because $50 \%$ of the nursing study program is (as a general requirement in Europe) situated in clinical placements, ${ }^{[5,15,16]}$ situations in local practice have a high degree of relevance to the total quality of the study program. However, the specificity of clinical placement and requirements in placement learning have remained unexplored in recent research: The operationalization of NTs' competencies was not seen as tailored to the situation in the clinical placement site. Nonetheless, the responses indicated the importance of the integration of theory and research into practice for learning in the clinical placement. Similarly, Terum and Heggen ${ }^{[21]}$ indicated that possible tensions exist within subjects at placement, implying need to handle a certain amount of controversy and uncertainty. Based on the core aspect of professional education, ${ }^{[20]}$ especially apprenticeship grounded in practitioners' professional skills in the work context, there are considerable implications for the nursing program, as well as for NTs.

Furthermore, the data pinpointed distinctions in curriculum relevance for placement learning, as well as its effective operationalization among campuses: Contextual opportunities and constraints had facilitative or obstructive effects on the initial professional development of the students. The responses also indicated that the quality of the interplay between the clinical and university settings was dependent on the educational institutions, with NTs occupying the primary position of responsibility in this complex interaction. In a dynamic real-world context, NTs operate at the intersection between a specific health-care environment and academia. Subsequently, the integration of a dynamic practice context into the development of theory, the integration of theory and research for real-world utilization, and stakeholders' involvement in decision-making could be seen as preconditions for securing quality in the described complexity.

\subsection{Widening the perspective}

NTs' field of practice, explicit and implicit responsibilities, and competency requirements imply, among other things, an appreciation of complexity, relational expertise, attunement to contextual conditions, and situational awareness. This-together with ongoing rapid changes in the health sector and the need for professional expertise to meet patients' demands for increased quality, efficiency, safety, and satisfaction — calls for further development of high-quality, up-to-date nursing education. The NT appears to be a critical
Based on the need for balancing potentially conflictual components of nursing education ${ }^{[39,40]}$ while bearing in mind the described issues in this paper and global trends, we believe the challenge is in enabling the teaching staff to apply the notion of critical thinking to professional education, ${ }^{[22]}$ particularly regarding placement learning. Yet, a variety of conditions exist in clinical placement, as revealed in the data (e.g., leadership, existing culture, level of competencies). We question whether this variation is influenced by the status of the health system and the total sociopolitical orientation. We also wonder whether the orientations and practices of nursing education institutions can be understood as a result of social, cultural, and political contexts within which nursing education operates and whether NTs' competencies can be seen as a product. It is noteworthy that the sociopolitical influences on educational and health institutions have not been explored in recent research.

\subsection{Methodological considerations}

This study points to the central importance of situational representativeness: The participants were selected based on their ability to provide information about the area under investigation - in this case, the NTs, mentors, and nursing students in the clinical placement. Therefore, the value of this research lies in the specific descriptions and themes developed in context of a specific site. The provided body of knowledge is found to be as closely matched as possible to the posited research questions. Furthermore, the triangulation of methods and sources was used to strengthen the study ${ }^{[47]}$ However, the results could be deemed sensitive to the specific context/culture and environment.

Conducting research within one's own field could reduce critical reasoning in situations, leading to low social scientific relevance. ${ }^{[4]}$ An interdisciplinary research team carried out this research, thereby decreasing the risk of the latter occurring and preventing the possibilities of personal biases impacting the study. All the researchers are known within the field, and two of the authors were previously employed at one of the campuses. Furthermore, conducting research on colleagues in their own workplace involves major ethical challenges. ${ }^{[27,28,49]}$ For this reason, issues connected with conducting research in one's own discipline or realm received special attention. The participants knew the researchers' motivation for the research, as well as the purpose and aim of the study. The participants' validations as well as communicative validity within the research team were established as described. 


\section{Conclusion}

This paper aimed to illuminate NTs' competencies and their operationalization in the context of clinical placement by exploring the challenges of being an NT, as experienced and articulated by NTs, nurse mentors, and nursing students. The operationalization of the key competencies of NTs in the context of their responsibility for students' placement learning is complex. This complexity can have various effects, facilitating or obstructing professional learning. The various components of the model established in this paper (see Figure 1) seem to provide realistic implications and challenges of the situation in the field of nursing education. Aspects of articulated challenges are directly connected to individual NTs' characteristics, combination of professional competencies, and ability to apply them to specific situations, whilst engaging with students' enthusiasm and aspirations, maintaining own clinical and understanding and, with regard to placement learning, working alongside the mentors.

However, this research clearly proposes that institutional and departmental contexts as well as professional contexts of nursing practice and nursing education influence both NTs and students. In the current climate of the health-care and educational systems, it is becoming increasingly difficult for an individual NT to deliver high-quality practical and theoretical nursing education single-handedly. We view working and learning together as central to integrating various aspects of professional knowledge and practice, and doing so requires cooperative and collective actions and a common strategy that supports good practices. To that end, this analysis draws attention to the further development of organized and structured cooperation in and across institutions on establishing and maintaining links among different contexts of nursing education. With regard to placement learning, the complementary competencies of NTs and mentors, which mesh across fields and domains of expertise, appeared to be a possible solution.

\section{ACKNOWLEDGeMENTS}

The authors express their gratitude to Dr. Lindy King, Associate Dean (Research Higher Degree programs) of the School of Nursing and Midwifery at Flinders University, for her helpful and stimulating discussions and editorial suggestions throughout this paper.

\section{Conflicts of InTEREST Disclosure}

The authors declare that there is no conflict of interest.

\section{REFERENCES}

[1] Abbott A. The system of professions: an essay on the division of labor. Chicago, IL: University of Chicago Press; 1988.

[2] Mulder M. Conceptions of professional competence. In: Billett $S$, Harteis $\mathrm{C}$, Gruber $\mathrm{H}$, editors. International handbook of research in professional and practice-based learning. New York: Springer; 2014. 107-139. http://dx.doi.org/10.1007/978-94-017-8 902-8_1

[3] Johnsen KØ, Aasgaard HS, Wahl AK, et al. Nurse educator competence: a study of Norwegian nurse educators' opinions of the importance and application of different nurse educator competence domains. J Nurs Educ. 2002; 41(7): 295-301. http: //dx . doi .org /10.3928/0148-4834-20020701-05

[4] Lee WS, Cholowski K, Williams AK. Nursing students' and clinical educators' perceptions of characteristics of effective clinical educators in an Australian university school of nursing. J Adv Nurs. 2002; 39(5): 412-420. http://dx. doi .org/10.1046/j.1365-2 $648.2002 .02306 . \mathrm{x}$

[5] Salminen L, Stolt M, Saarikoski M, et al. Future challenges for nursing education - a European perspective. Nurse Educ Today. 2010; 30(3): 233-238. http://dx.doi.org/10.1016/j.nedt. 2009.1 1.004

[6] Tigelaar DEH, Dolmans DHJM, Wolfhagen IHAP, et al. The development and validation of a framework for teaching competencies in higher education. High Educ. 2004; 48(2): 253-268. http: //dx.doi.org/10.1023/B:HIGH.0000034318.74275.e4

[7] Saarikoski M, Warne T, Kaila P, et al. The role of the nurse teacher in clinical practice: an empirical study of Finnish stu- dent nurse experiences. Nurse Educ Today. 2009; 29(6): 595-600. http://dx.doi.org/10.1016/j.nedt.2009.01.005

[8] Ramsburg L, Childress R. An initial investigation of the applicability of the Dreyfus skill acquisition model to the professional development of nurse educators. Nurs Educ Perspect. 2012; 33(5): 312-316. http://dx.doi.org/10.5480/1536-5026-33.5.312

[9] Halstead JA, Bonnel W, Chamberlain B, et al. Core competencies of nurse educators [Internet]. National League for Nursing. Task Group on Nurse Educator Competencies. 2006. Available from: http: //www.nln.org/profdev/pdf/corecompetencies.pdf

[10] Australian Nurse Teachers' Society (ANTS). Australian nurse teacher professional practice standards [Internet]. 2010. Available from: http://www. ants.org.au1

[11] Guy J, Taylor C, Roden J, et al. Reframing the Australian nurse teacher competencies: do they reflect the "REAL" world of nurse teacher practice? Nurse Educ Today. 2011; 31(3): 231-237. http: //dx.doi.org/10.1016/j.nedt.2010.10.025

[12] Entwistle N, McCune V, Hounsell J. Approaches to studying and perceptions of university teaching- learning environments: concepts, measures and preliminary findings. ETL Project Occasional Report 1, ETL- Project, Universities of Edinburgh, Coventry and Durham; 2002.

[13] Potter PA, Perry AG, Stockert P, et al. Fundamentals of nursing. 8th ed. St. Louis, MO: Elsevier; 2013.

[14] Brante T. The professional landscape: the historical development of professions in Sweden. Professions \& Professionalism. 2013; 3(2): 1-16. http://dx.doi.org/10.7577/pp. 558 
[15] Bologna Declaration. The Bologna Declaration of 19 June 1999: Joint declaration of the European Ministers of Education [Internet], Bologna; 1999. Available from: http//eceuropa.eu/educatio n/policies/educ/bologna/bologna.pdf

[16] European Ministers of Education. The Bologna process, 2012: the European higher education area in 2012: Bologna process; implementation report [Internet]. 2012. http://dx.doi.org/10.2797 /81203

[17] Biggs J, Tang C. Teaching for quality learning at university. 4th ed. Maidenhead, United Kingdom: McGraw-Hill and Open University Press; 2011.

[18] Benner P, Sutphen M, Leonard V, et al. Educating nurses: a call for radical transformation. San Francisco, CA: Jossey-Bass; 2010.

[19] Illeris K, editor. International perspectives on competence development: developing skills and capabilities. New York, NY: Routledge; 2009.

[20] Sullivan WM. Work and integrity: the crisis and promises of professionalism in America. 2nd ed. San Francisco, CA: Jossey-Bass; 2005.

[21] Terum LI, Heggen K. Identification with the social work profession: the impact of education. Br J Soc Work. 2015: 1-16. http: //dx.doi.org/10.1093/bjsw/bcv026

[22] Colby A, Ehrlich T, Sullivan WM, et al. Rethinking undergraduate business education: liberal learning for the profession. Stanford, CA: The Carnegie Foundation for the Advancement of Teaching; 2011.

[23] Lave J, Wenger E. Situated learning: legitimate peripheral participation. Cambridge, UK: Cambridge University Press; 1991. http://dx.doi.org/10.1017/CB09780511815355

[24] Vygotsky LS. Interaction between learning and development (LopezMorillas M, translator). In: Cole M, John-Steiner V, Scribner S, et al., editors. Mind in society: the development of higher psychological processes. Cambridge, MA: Harvard University Press; 1978. p. 79-91.

[25] Gadamer HG. On the circle of understanding. In: Connolly J, Keutner T, editors. Hermeneutics versus science? Three German views. Notre Dame, IN: University of Notre Dame Press; 1988. p. 68-78.

[26] Peters K, Jackson D, Andrew S, et al. Burden versus benefit: continuing nurse academics' experiences of working with sessional teachers. Contemp Nurse. 2011; 38(1-2): 35-44. http://dx . doi .org/10. 5172/conu.2011.38.1-2.35

[27] Brinchmann BS. Etikk i sykepleien [Ethics in nursing]. (Vol. 2). Oslo, Norway: Gyldendal Akademiske; 2010. PMid:26781122

[28] Malterud K. Kvalitative metoder i medisinskforskning, En innføring [Qualitative methods in medical research: an introduction]. (Vol. 3). Oslo, Norway: Universitetsforlaget; 2013.

[29] Kvale S, Brinkmann S. The qualitative research interview. Oslo, Norway: Gyldendal Akademiske; 2012.

[30] Johannesen A, Tufte PA, Christoffersen L. Introduksjon til samfunnsvitenskapelig metode [Introduction to social science methodology]. Oslo, Norway: Abstraktforlag AS; 2011.

[31] MAXQDA 11 [Computer software]. 2015. Available from: http://www.maxqda.com/download/New-Features-in-MAX QDA-11.pdf

[32] Spreitzer GM. Psychological empowerment in the workplace: dimensions, measurement, and validation. Acad Manage J. 1995; 38(5): 1442-1465. http://dx.doi.org/10.2307/256865
[33] Hebenstreit JJ. Nurse educator perceptions of structural empowerment and innovative behavior. Nurs Educ Perspect. 2012; 33(5): 297 301. http://dx.doi.org/10.5480/1536-5026-33.5.297

[34] Tveiten S, Boge K, editors. Empowerment i helse, ledelse og pedagogikk: Nye perspektiv [Empowerment in health, management and pedagogy: new perspective]. Oslo, Norway: Gyldendal; 2014.

[35] Brancato VC. Psychological empowerment and use of empowering teaching behaviors among baccalaureate nursing faculty. J Nurs Educ. 2007; 46(12): 537-544.

[36] Simons RJP, Ruijters CPM. The real professional is a learning professional. In: Billett S, Harteis C, Gruber H, editors. International handbook of research in professional and practice-based learning. New York: Springer; 2014. p. 955-985. http://dx.doi.org/10. 1007/978-94-017-8902-8_1

[37] Griffin G, Green T, Medhurst P. The relationship between the process of professionalization in academe and inter disciplinarity: a comparative study of eight European countries. Kingston upon Hull, United Kingdom: University of Hull; 2005.

[38] Hinshaw ASA. Continuing challenge: the shortage of educationally prepared nursing faculty. OJIN. 2001; 6(1): 1-9.

[39] Cowan DT, Norman I, Coopamah VP. Competence in nursing practice: a controversial concept - a focused review of literature. Nurse Educ Today. 2005; 25(5): 355-362. http://dx.doi.org/10.10 $16 / j$.nedt. 2005.03 .002

[40] Thompson DR. Is nursing viable as an academic discipline? Nurse Educ Today. 2009; 29(7): 694-697. http://dx.doi.org/10.10 $16 /$ j.nedt . 2009.03 .007

[41] McNamara MS. Academic leadership in nursing: legitimating the discipline in contested spaces. J Nurs Manag. 2009; 17(4): 484-493. http://dx.doi.org/10.1111/j.1365-2834.2009.01014.x

[42] Barr H, Koppel I, Reeves S, et al. Effective interprofessional education: argument, assumption and evidence. Oxford, United Kingdom: Blackwell; 2005. http://dx.doi.org/10.1002/97804707764 45

[43] Reeves S, Zwarenstein M, Goldman J, et al. Interprofessional education: effects on professional practice and health care outcomes. Cochrane Database Syst Rev. 2009. http://dx.doi.org/10.10 02/14651858. CD002213.pub2

[44] Löfmark A, Thorkildsen K, Råholm MB, et al. Nursing students' satisfaction with supervision from preceptors and teachers during clinical practice. Nurse Educ Pract. 2012; 12(3): 164-169. http://dx.doi.org/10.1016/j.nepr.2011.12.005

[45] McKenna L, Wellard S. Mothering: an unacknowledged aspect of undergraduate clinical teachers' work in nursing. Adv Health Sci Educ Theory Pract. 2009; 14(2): 275-285. http://dx.doi.org/1 0.1007/s10459-008-9109-3

[46] Colby A, Sullivan WM. Formation of professionalism and purpose: perspectives from the preparation for the professions program. U St Thomas LJ. 2008; 5(2): 404-427.

[47] Patton MQ. Qualitative evaluation and research methods. 3rd ed. Thousand Oaks, CA: Sage; 2002.

[48] Molander A, Smeby JC. Profesjonstudier II [The study of professions II]. Oslo, Norway: Universitetsforlaget; 2013. 192 p.

[49] Kvale S, Brinkmann S. Inter Views: learning the craft of qualitative research interviewing. Los Angeles, CA: Sage; 2009. 